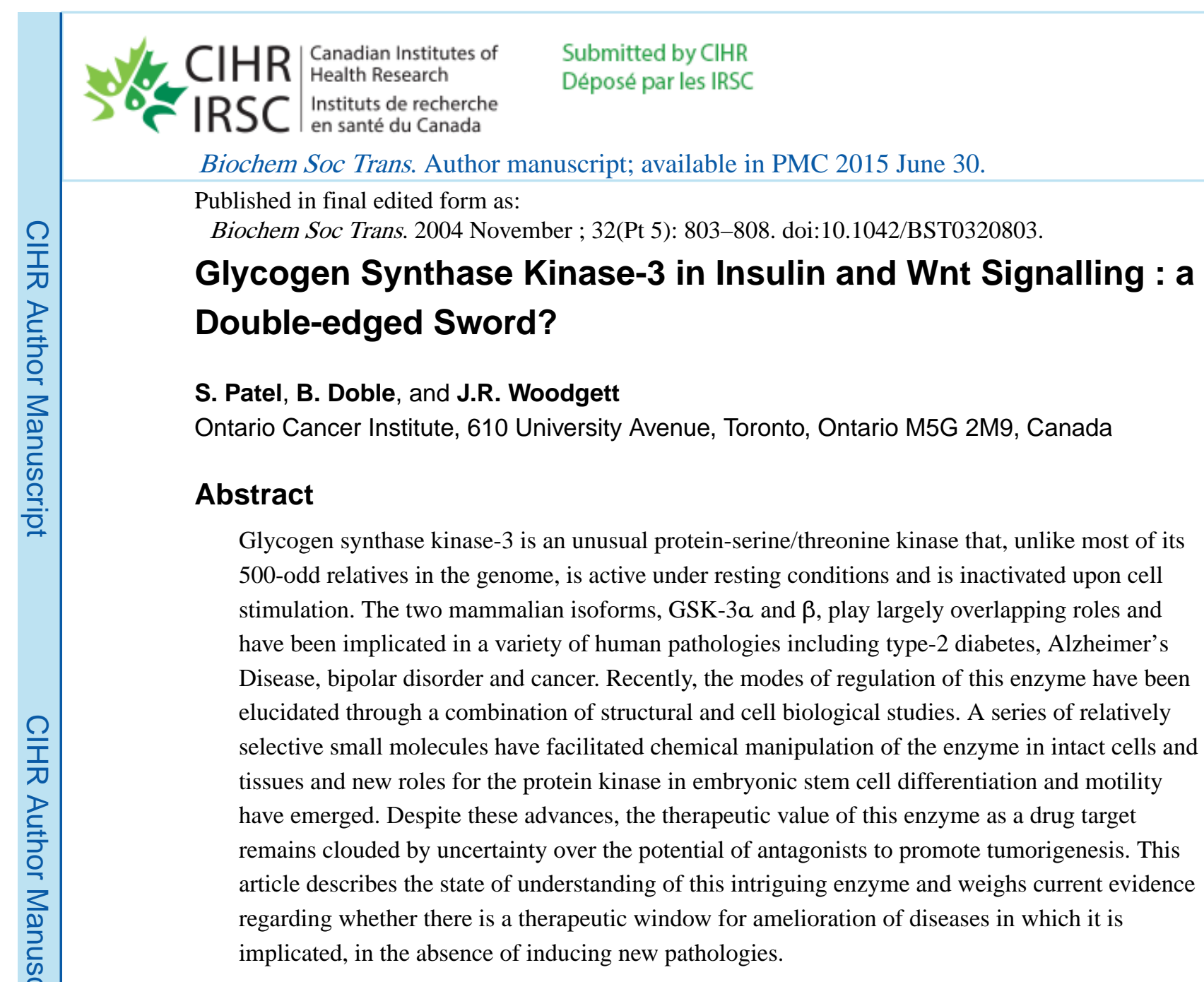

\title{
Keywords
}

protein kinase; diabetes; signal transduction; glycogen; $\beta$-catenin

\section{Metabolic regulation}

Glycogen synthase kinase-3 (GSK-3) was originally identified as one of several protein kinases capable of phosphorylating the rate-limiting enzyme of glycogen deposition, glycogen synthase (GS) [1]. In peripheral tissues, insulin modulates glycogen metabolism through a coordinated increase in glucose transport and glycogen synthesis. Insulin stimulates glycogen synthesis by activating GS, through dephosphorylation of GS particularly at the sites targeted by GSK-3 [2]. This action of insulin is mediated by simultaneously inhibiting GSK-3 kinase activity and by activating one of the glycogenassociated forms of protein-phosphatase 1 . While the identity of the specific phosphatase and the mechanism by which it is activated by insulin remains elusive, the signalling pathway by which insulin inhibits GSK-3 has now been established. It was first shown that in rat adipocytes, insulin treatment rapidly inactivated a protein kinase that was capable of phosphorylating ATP-citrate lyase, and it was later found that this protein kinase was GSK-3a [3, 4]. Subsequently, it was shown that the insulin-mediated inhibition of both isoforms of GSK-3 ( $\alpha$ and $\beta$ ) was mediated through a phosphorylation-dependent mechanism, with the phosphorylation of each isoform occurring at an serine (S) residue in 
the N-terminal lobe of the protein kinase (S21 for GSK-3a and S9 for GSK-3 $\beta$ ) [5]. Several protein kinases can phosphorylate these residues, namely the AGC kinases, p70 ribosomal S6 kinase, p90 ribosomal S6 kinase, protein kinase A and protein kinase C. However, insulin mediated phosphorylation and inhibition of GSK-3 in vivo is primarily mediated through activation of phosphatidylinositol 3-kinase (PI3' kinase)/protein kinase B (PKB) pathway $[5,6]$. The degree of inhibition of GSK-3 activity by insulin in skeletal muscle is $\sim 50 \%$.

The mechanism by which N-terminal serine phosphorylation inhibits GSK-3 activity relates to an unusual property of GSK-3 in phosphorylating its substrates. The minimal recognition motif for phosphorylation by GSK-3 is $\mathbf{S} / \mathbf{T X X X} \underline{\mathrm{S} / \mathrm{T}}(\mathrm{P})$, where $\mathrm{X}$ is any amino acid. In order for GSK-3 to efficiently phosphorylate its substrate proteins, it requires that the substrate is previously phosphorylated (by another protein kinase) at a serine or threonine residue located four residues C-terminal (underlined in consensus motif) to the site of GSK-3 phosphorylation (S/T residue in bold) [7].

Through biochemical and structural studies it was demonstrated that the N-terminal of GSK-3, the structure of which is relatively disordered in resting cells, upon phosphorylation at $\mathrm{S}$, folds back on itself, forming electrostatic interactions with several residues (including arginine 96) that are involved in binding the priming phosphate. This conformation occludes the active site, preventing binding of primed substrates. Thus, $\mathrm{N}$-terminal serine phosphorylation acts as a 'pseudosubstrate' competitive inhibitor [8-10]. Therefore, it appears that GSK-3 exists in a constitutively active conformation in resting cells, and that inhibition of GSK-3 activity (through serine phosphorylation) is a means by which extracellular stimuli regulate this protein kinase. However, as described below, there are additional means of regulating GSK-3 activity distinct from phosphorylation (e.g. subcellular localisation, binding to scaffold proteins).

In addition to its role in glycogen metabolism, GSK-3 also modulates other metabolic processes including the rate of protein synthesis. Eukaryotic initiation factor $2 \mathrm{~B}$ (eIF2B) is a guanine nucleotide exchange factor that is important for initiation of translation.

Phosphorylation of eIF2B by GSK-3 inhibits its guanine-nucleotide exchange activity. This effect, like GS, is reversed by insulin through the PI3K/PKB dependent inhibition of GSK-3 and dephosphorylation of eIF2B, leading to the activation of protein synthesis [11].

\section{Diabetes}

Type 2 Diabetes Mellitus (T2DM) is a serious metabolic disorder that is characterised by the inability to respond to the hormone insulin (insulin resistance) as well as the failure of the pancreatic $\beta$ cells to compensate for insulin resistance by increasing insulin secretion. These two defects lead to the loss of control of glucose homeostasis, resulting in hyperglycaemia and further complications such as kidney nephropathy and blindness. T2DM diabetes is a rapidly growing problem and its worldwide frequency is projected to rise by $6 \%$ per year.

Glucose/insulin clamp studies, muscle biopsies/cell culture and NMR analyses have revealed that one of the major features of T2DM is the impairment of both basal- and insulinstimulated glucose metabolism in peripheral tissues (skeletal muscle, liver). Compared to 
normal tissues, the muscle tissue from Type 2 diabetic patients has reduced glycogen deposition that is correlated with decreased activity of GS and impaired responsiveness to insulin $[12,13]$.

While there is as yet no evidence for genetic mutations in the two GSK-3 genes associated with the pathogenesis of T2DM [14], there are studies demonstrating increased protein levels as well as activity of GSK-3 in skeletal muscle of type 2 diabetics, and in adipose tissues of obese diabetic mice $[15,16]$. GSK-3 has also been implicated as a negative regulator of insulin signalling through serine phosphorylation of IRS-1, making it a poorer substrate for tyrosine phosphorylation by the insulin receptor, thereby attenuating insulin signalling [17].

Consequently, the therapeutic potential of GSK-3 inhibitors has become a major area of pharmaceutical interest. Indeed, there are several classes of inhibitors that are reportedly selective for GSK-3. Only a few of these GSK-3 inhibitors have been utilised in examining the role of GSK-3 in metabolism, and they are described below.

Lithium chloride is a widely used inhibitor of GSK-3 in vitro and in vivo and has been shown to have some insulin-mimetic properties in various cells types. For instance, lithium chloride stimulates glucose transport and glycogen synthesis in adipocyte and muscle cell lines [18, 19]. SB 216763 and SB 415286 are cell-permeable maleimide compounds developed by Glaxo Smith Kline that selectively inhibit GSK-3 [20]. Treatment of liver cells, L6 muscle cells and adipocytes with these compounds stimulates glycogen synthesis [20,21]. All three compounds also mimic insulin's ability to regulate hepatic gene transcription, namely the repression PEPCK and G6Pase, rate-limiting enzymes of gluconeogenesis [22].

Based on these observations, studies of GSK-3 inhibitors have recently been extended into rodent models of diabetes and rhesus monkeys. Chiron has developed several potent and specific inhibitors of GSK-3. CHIR98014, CHIR 98023 and CHIR 99021 are aminopyrimidine derivatives that, in cultured human muscle cells and hepatocytes, stimulate the activation of GS and glycogen synthesis [23, 24]. Oral administration of these compounds in Zucker diabetic ( $f a / f a$ ) rats reduced overall glucose and insulin concentrations in an oral glucose tolerance test, demonstrating an improvement in glucose disposal. This is accompanied by stimulation of GS in both the muscle and liver, with a significant increase in liver glycogen synthesis. Inhibition of gluconeogenesis was also evident, as demonstrated by the reduction in fasting glucose levels in response to an overnight treatment of rats with the inhibitor, possibly reflecting its ability to suppress hepatic expression of PEPCK and G6Pase [25]. Since these exciting findings, Chiron has developed improved derivatives of the GSK-3 inhibitors that have not only been characterised in the ZDF rats or ob/ob mice, but also in 'non-leptin/leptin receptor-defective' diabetic rodents as well as diabetic rhesus monkeys [26]. 


\section{Wnt signalling - the other occupation of GSK-3}

The Wnts, a family of secreted glycoprotein ligands, are essential for proper embryonic development due to their role in the regulation of cellular proliferation, differentiation, motility and polarity [27]. One way that Wnts can mediate a response is through the stabilization of a specific pool of $\beta$-catenin that is usually targeted for degradation. Stabilization of this $\beta$-catenin results in its accumulation in the cytosol and ultimately the nucleus where it binds architectural transcription factors of the TCF/LEF family to activate transcription of Wnt target genes [28]. GSK-3 plays a central role in this canonical Wnt signal transduction pathway since its phosphorylation of $\beta$-catenin on key residues is required for $\beta$-catenin's ubiquitination and proteasomal degradation in "resting" cells (Fig. 2). Conversely, upon Wnt treatment, GSK-3 must be prevented from phosphorylating $\beta$ catenin to bypass the $\beta$-catenin degradation machinery.

Phosphorylation of $\beta$-catenin by GSK-3 occurs in a multi-protein complex containing, in part, axin, adenomatous polyposis coli (APC) and $\beta$-catenin [29]. Mutations in axin, APC and $\beta$-catenin have been linked to numerous types of human cancer including those of the breast, skin, liver and colon [30]. Although once thought to be one of the few unprimed substrates for GSK-3, $\beta$-catenin has been shown to be primed at S45 by casein kinase I (CKI), allowing efficient subsequent serial phosphorylations by GSK-3 on residues T41, S37 and S33 [31]. It is the phosphorylation of $\beta$-catenin on S33 and S37 that appears to be essential for $\beta$-catenin's recognition by the ubiquitin ligase $\beta$ - TrCP, which targets it for subsequent degradation [32]. Mutations of $\beta$-catenin at the residues phosphorylated by CKI or GSK-3 sites have been found in numerous types of cancer including colorectal cancer, melanoma, pilomatricoma, and hepatocellular and ovarian carcinoma [30]. Although it has been proposed that regulated phosphorylation of S45 by CKI might serve as a switch to modulate $\beta$-catenin's degradation [33], a recent study in Drosophila cells strongly suggests that the phosphorylation status of this residue does not change upon wingless (wg; the Drosophila Wnt ortholog) stimulation [34]. Similar findings have been found in mouse embryonic stem cells (ESCs) in which both isoforms of GSK-3 have been "knocked out". These cells have a massive increase in cytoplasmic and nuclear $\beta$-catenin that remains phosphorylated on S45 regardless of treatment with Wnt-3a and is unphosphorylated on residues 33, 37 and 41 as expected (B. Doble et al., in preparation).

Axin and APC are also GSK-3 substrates. The phosphorylation of Axin by GSK-3 has been reported to increase Axin's stability and affinity for $\beta$-catenin [35-37]. It has been proposed that the mechanism of $\beta$-catenin stabilization in wnt signalling might depend more on the regulation of axin stability rather than that of $\beta$-catenin itself since it appears that axin might be the limiting factor regulating $\beta$-catenin degradation [38]. The phosphorylation of APC by GSK-3 also increases APC binding to $\beta$-catenin [39].

The Wnt-induced mechanism precluding GSK-3's phosphorylation of $\beta$-catenin remains elusive. Wnt treatment of human embryonic kidney 293 cells that was effective in stabilizing $\beta$-catenin, caused a reduction in GSK-3 activity, as measured by immunoprecipitating endogenous GSK-3 and assaying its activity in vitro [40]. This reduction in activity was not as a result of $\mathrm{S} 9 / 21$ phosphorylation. Insulin treatment, although causing a reduction in 
GSK-3 activity and increased S9 phosphorylation, did not affect $\beta$-catenin levels in the same cells. Thus, it appears that the GSK-3 involved in $\beta$-catenin regulation is insulated from other signalling pathways and is regulated in a unique manner. Recent experiments using Drosophila cells came to the same conclusions as the 293 studies; namely that wg treatment sufficient to stabilize armadillo (arm; Drosophila $\beta$-catenin ortholog) does not result in S9 phosphorylation of the Drosophila GSK-3 ortholog, shaggy (sgg)/Zeste-white3, and that insulin-mediated inactivation of sgg through $\mathrm{S} 9$ phosphorylation does not impact on arm levels [34] [41]. Further underscoring that S9 phosphorylation is not essential for wg signalling, a sgg minigene with an S9A mutation is able to rescue mutant sgg in developing larvae without developmental anomalies [41]. In a mammalian cell system, mouse ESCs reexpressing a S21A mutant form of GSK-3 $a$ in a GSK-3 null background have normalized cytosolic $\beta$-catenin levels compared to the very high levels in the null cells and respond to Wnt3A with increased cytosolic $\beta$-catenin (B. Doble et al., in preparation).

Recently, Sato and colleagues reported that a small molecule inhibitor of GSK-3, bromoindirubin-3' -oxime (BIO), could maintain the pluripotentiality of ESCs of mouse and human origin [42]. The BIO effect on pluripotency is suggested to be due to increased Wnt signalling resulting from GSK-3 inhibition. That the effect is specific to inhibition of GSK-3 is supported by work with mouse ESCs totally lacking GSK-3 that are extremely limited in their differentiation potential (B. Doble et al., in preparation). These findings are perhaps not surprising since it has been shown that increased wnt signalling appears to favour selfrenewal in other types of stem cells including hematopoeitic stem cells and mammary progenitor cells and that mouse ESCs with mutations in APC are also unable to differentiate properly [43] [44] [45]. It has been suggested that wnt's role in stem cell maintenance and self renewal may explain why mutations in wnt pathway proteins are found frequently in certain types of cancer [46].

\section{GSK-3 as a therapeutic target}

Preliminary data from the GSK-3 inhibitor programs (carried out as a short - and long term administration) demonstrates that these compounds can reduce hyperglycaemia and improve insulin sensitivity [26]. While this proof-of-principle in inhibiting GSK-3 as a means to relieve the effects of T2DM is very promising, there are serious concerns regarding the potential of GSK-3 inhibitors as therapeutics: Firstly, the specificity of these compounds is not restricted to GSK-3. For example, lithium has many other effects, inhibiting adenylate cyclase, inositol monophosphatase as well as activating JNK [47-49]. SB 216763, SB 415286 and the Chiron inhibitors have been classed as more selective inhibitors of GSK-3 as they have been shown not to affect the activity of 24 other protein kinases in vitro. However, this does not prove complete specificity and many inhibitors of this class tend to exhibit some activity against the cyclin-dependent kinases.

Secondly and more importantly from a therapeutic standpoint, GSK-3 also is a key player in the Wnt signalling pathway which is dysregulated in many human cancers. GSK-3 inhibitors would be expected to mimic Wnt action, potentially promoting oncogenesis (see Wnt signalling section). Indeed, all of these compounds have been shown to elevate the levels of $\beta$-catenin in various cell lines. Despite this, no deleterious effects of these compounds have 
been formally demonstrated as yet in the diabetic rodent studies. While there are some indications that the Chiron inhibitors elevate $\beta$-catenin levels in mice (as mentioned in the material and methods of [24]), the relative induction compared to Wnt was not determined. One will have to assess the effects of long-term exposure of the GSK-3 inhibitors on the incidence of tumours. However, it is possible that mild inhibition of GSK-3 ( 30-40\%) is sufficient for therapeutic insulin-resensitization of the muscle and liver tisues in T2DM, and that a much stronger degree of inactivation (> 75\%) of GSK-3 may be required to invoke growth-promoting effects. This is supported by the finding that $\beta$-catenin levels are largely unaffected in embryos that lack GSK-3 3 [50] and that disruption of at least three of the four GSK-3 alleles is necessary to begin to impact $\beta$-catenin in embryonic stem cells (B. Doble et al., in preparation).

\section{Abbreviations used}

\begin{tabular}{|c|c|}
\hline APC & adenomatous polyposis coli \\
\hline arm & armadillo \\
\hline BIO & bromo-indirubin- $3^{\prime}$-oxime \\
\hline CKI & casein kinase I \\
\hline eIF2B & eukaryotic initiation factor $2 \mathrm{~B}$ \\
\hline ESC & embryonic stem cell \\
\hline G6Pase & glucose 6-phosphatase \\
\hline GS & glycogen synthase \\
\hline GSK-3 & glycogen synthase kinase- 3 \\
\hline IRS-1 & insulin receptor substrate- 1 \\
\hline PDK1 & phosphoinositide-dependent kinase 1 \\
\hline PEPCK & phosphoenolpyruvate carboxykinase \\
\hline PI3K & phosphatidylinositol $3^{\prime}$ kinase \\
\hline PKB & protein kinase $\mathrm{B}$ \\
\hline sgg & shaggy \\
\hline T2DM & type-2 diabetes mellitis \\
\hline wg & wingless \\
\hline
\end{tabular}

\section{References}

1. Embi N, Rylatt DB, Cohen P. Eur J Biochem. 1980; 107:519-27. [PubMed: 6249596]

2. Parker PJ, Caudwell FB, Cohen P. Eur J Biochem. 1983; 130:227-34. [PubMed: 6402364]

3. Ramakrishna S, Benjamin WB. J Biol Chem. 1988; 263:12677-81. [PubMed: 3045124] 
4. Hughes K, Ramakrishna S, Benjamin WB, Woodgett JR. Biochem J. 1992; 288 ( Pt 1):309-14. [PubMed: 1332698]

5. Cohen P. Philos Trans R Soc Lond B Biol Sci. 1999; 354:485-95. [PubMed: 10212493]

6. Jope RS, Johnson GV. Trends Biochem Sci. 2004; 29:95-102. [PubMed: 15102436]

7. Fiol CJ, Mahrenholz AM, Wang Y, Roeske RW, Roach PJ. J Biol Chem. 1987; 262:14042-8. [PubMed: 2820993]

8. Frame S, Cohen P, Biondi RM. Mol Cell. 2001; 7:1321-7. [PubMed: 11430833]

9. Dajani R, Fraser E, Roe SM, Young N, Good V, Dale TC, Pearl LH. Cell. 2001; 105:721-32. [PubMed: 11440715]

10. Bax B, Carter PS, Lewis C, Guy AR, Bridges A, Tanner R, Pettman G, Mannix C, Culbert AA, Brown MJ, Smith DG, Reith AD. Structure (Camb). 2001; 9:1143-52. [PubMed: 11738041]

11. Proud CG. Prog Mol Subcell Biol. 2001; 26:95-114. [PubMed: 11575168]

12. Shulman GI, Rothman DL, Jue T, Stein P, DeFronzo RA, Shulman RG. N Engl J Med. 1990; 322:223-8. [PubMed: 2403659]

13. Cline GW, Rothman DL, Magnusson I, Katz LD, Shulman GI. J Clin Invest. 1994; 94:2369-76. [PubMed: 7989593]

14. Hansen L, Arden KC, Rasmussen SB, Viars CS, Vestergaard H, Hansen T, Moller AM, Woodgett JR, Pedersen O. Diabetologia. 1997; 40:940-6. [PubMed: 9267989]

15. Nikoulina SE, Ciaraldi TP, Mudaliar S, Mohideen P, Carter L, Henry RR. Diabetes. 2000; 49:26371. [PubMed: 10868943]

16. Eldar-Finkelman H, Schreyer SA, Shinohara MM, LeBoeuf RC, Krebs EG. Diabetes. 1999; 48:1662-6. [PubMed: 10426388]

17. Eldar-Finkelman H, Krebs EG. Proc Natl Acad Sci U S A. 1997; 94:9660-4. [PubMed: 9275179]

18. Tabata I, Schluter J, Gulve EA, Holloszy JO. Diabetes. 1994; 43:903-907. [PubMed: 8013755]

19. Orena SJ, Torchia AJ, Garofalo RS. J Biol Chem. 2000; 275:15765-72. [PubMed: 10748179]

20. Coghlan MP, Culbert AA, Cross DA, Corcoran SL, Yates JW, Pearce NJ, Rausch OL, Murphy GJ, Carter PS, Roxbee Cox L, Mills D, Brown MJ, Haigh D, Ward RW, Smith DG, Murray KJ, Reith AD, Holder JC. Chem Biol. 2000; 7:793-803. [PubMed: 11033082]

21. MacAulay K, Hajduch E, Blair AS, Coghlan MP, Smith SA, Hundal HS. Eur J Biochem. 2003; 270:3829-38. [PubMed: 12950267]

22. Lochhead PA, Coghlan M, Rice SQ, Sutherland C. Diabetes. 2001; 50:937-46. [PubMed: 11334436]

23. Nikoulina SE, Ciaraldi TP, Mudaliar S, Carter L, Johnson K, Henry RR. Diabetes. 2002; 51:21908. [PubMed: 12086949]

24. Cline GW, Johnson K, Regittnig W, Perret P, Tozzo E, Xiao L, Damico C, Shulman GI. Diabetes. 2002; 51:2903-10. [PubMed: 12351425]

25. Ring DB, Johnson KW, Henriksen EJ, Nuss JM, Goff D, Kinnick TR, Ma ST, Reeder JW, Samuels I, Slabiak T, Wagman AS, Hammond ME, Harrison SD. Diabetes. 2003; 52:588-95. [PubMed: 12606497]

26. Wagman AS, Johnson KW, Bussiere DE. Curr Pharm Des. 2004; 10:1105-37. [PubMed: 15078145]

27. Miller JR. Genome Biol. 2002; 3:REVIEWS3001. [PubMed: 11806834]

28. Brantjes H, Barker N, van Es J, Clevers H. Biol Chem. 2002; 383:255-61. [PubMed: 11934263]

29. Hinoi T, Yamamoto H, Kishida M, Takada S, Kishida S, Kikuchi A. J Biol Chem. 2000; 275:34399-406. [PubMed: 10906131]

30. Giles RH, van Es JH, Clevers H. Biochim Biophys Acta. 2003; 1653:1-24. [PubMed: 12781368]

31. Doble BW, Woodgett JR. J Cell Sci. 2003; 116:1175-86. [PubMed: 12615961]

32. Fuchs SY, Spiegelman VS, Kumar KG. Oncogene. 2004; 23:2028-36. [PubMed: 15021890]

33. Amit S, Hatzubai A, Birman Y, Andersen JS, Ben-Shushan E, Mann M, Ben-Neriah Y, Alkalay I. Genes Dev. 2002; 16:1066-76. [PubMed: 12000790]

34. Matsubayashi H, Sese S, Lee JS, Shirakawa T, Iwatsubo T, Tomita T, Yanagawa S. Mol Cell Biol. 2004; 24:2012-24. [PubMed: 14966281] 
35. Willert K, Shibamoto S, Nusse R. Genes Dev. 1999; 13:1768-73. [PubMed: 10421629]

36. Yamamoto H, Kishida S, Kishida M, Ikeda S, Takada S, Kikuchi A. J Biol Chem. 1999; 274:10681-4. [PubMed: 10196136]

37. Jho E, Lomvardas S, Costantini F. Biochem Biophys Res Commun. 1999; 266:28-35. [PubMed: 10581160]

38. Tolwinski NS, Wieschaus E. Trends Genet. 2004; 20:177-81. [PubMed: 15041171]

39. Rubinfeld B, Albert I, Porfiri E, Fiol C, Munemitsu S, Polakis P. Science. 1996; 272:1023-6. [PubMed: 8638126]

40. Ding VW, Chen RH, McCormick F. J Biol Chem. 2000; 275:32475-81. [PubMed: 10913153]

41. Papadopoulou D, Bianchi MW, Bourouis M. Mol Cell Biol. 2004; 24:4909-19. [PubMed: 15143183]

42. Sato N, Meijer L, Skaltsounis L, Greengard P, Brivanlou AH. Nat Med. 2004; 10:55-63. [PubMed: 14702635]

43. Liu BY, McDermott SP, Khwaja SS, Alexander CM. Proc Natl Acad Sci U S A. 2004; 101:415863. [PubMed: 15020770]

44. Rattis FM, Voermans C, Reya T. Curr Opin Hematol. 2004; 11:88-94. [PubMed: 15257024]

45. Kielman MF, Rindapaa M, Gaspar C, van Poppel N, Breukel C, van Leeuwen S, Taketo MM, Roberts S, Smits R, Fodde R. Nat Genet. 2002; 32:594-605. [PubMed: 12426568]

46. Marx J. Science. 2003; 301:1308-10. [PubMed: 12958339]

47. Marmol F, Carbonell L, Cuffi ML, Forn J. Eur J Pharmacol. 1992; 226:93-96. [PubMed: 1356811]

48. Masana MI, Bitran JA, Hsiao JK, Potter WZ. J Neurochem. 1992; 59:200-205. [PubMed: 1319465]

49. Berridge MJ, Downes CP, Hanley MR. Cell. 1989; 59:411-419. [PubMed: 2553271]

50. Hoeflich KP, Luo J, Rubie EA, Tsao MS, Jin O, Woodgett JR. Nature. 2000; 406:86-90. [PubMed: 10894547] 


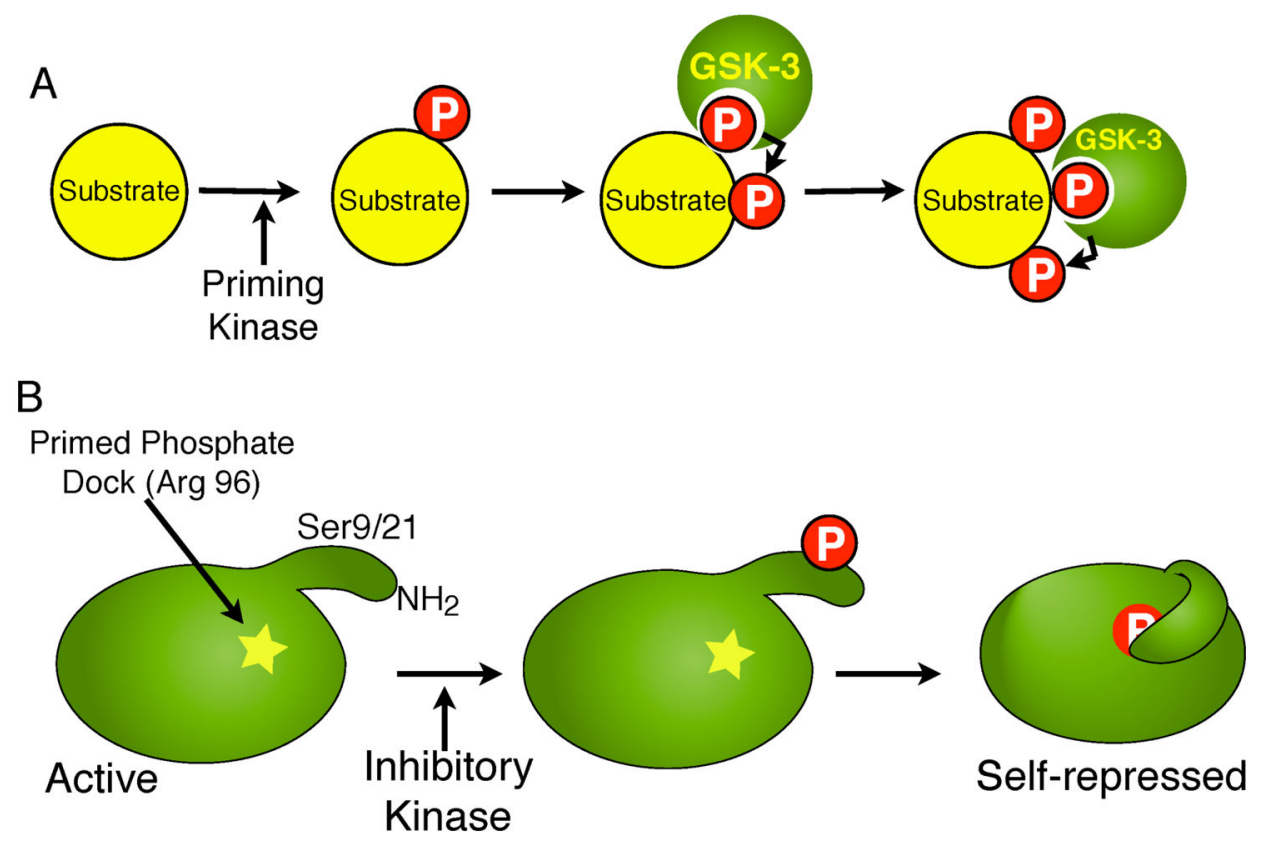

Fig. 1.

A. GSK-3 preferentially phosphorylates substrates that are pre-phosphorylated by a priming kinase. For example, in the case of the GSK-3 substrate $\beta$-catenin, phosphorylation by CKI on S45 primes it for sequential phosphorylation on T41, S37 and S33 by GSK-3. B. Pseudosubstrate inactivation of GSK-3. The N-termini of GSK-3 $a$ and $\beta$ contain serine residues ( $\mathrm{S} 21$ and $\mathrm{S} 9$, respectively) that when phosphorylated by an inhibitory kinase, serve as primed-pseudosubstrates that can occupy the substrate binding pocket of GSK-3, inhibiting its activity towards true substrates. 


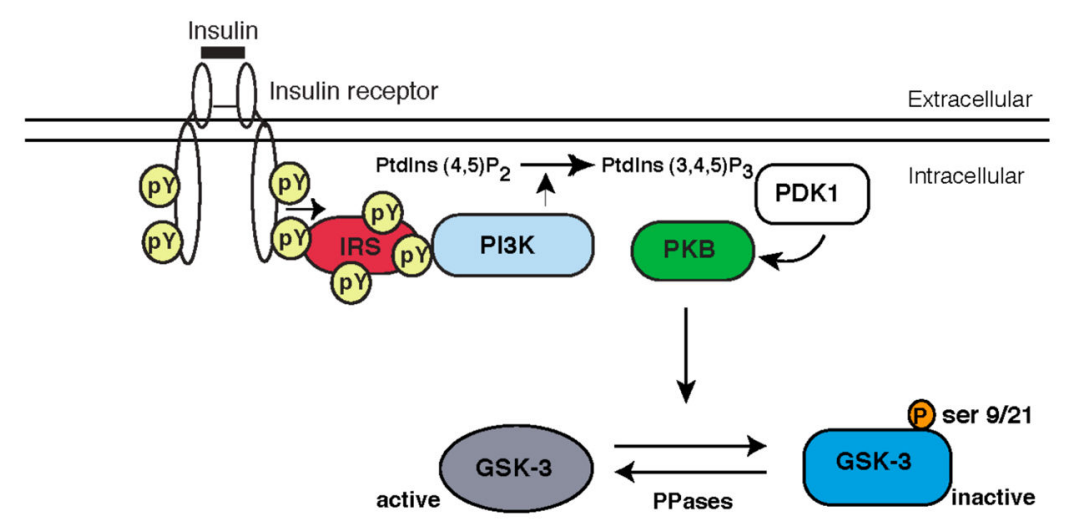

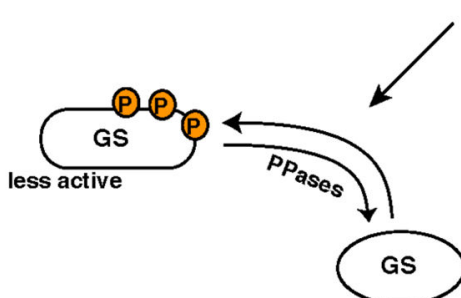

more active

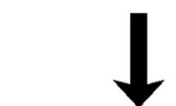

Regulation of glycogen metabolism
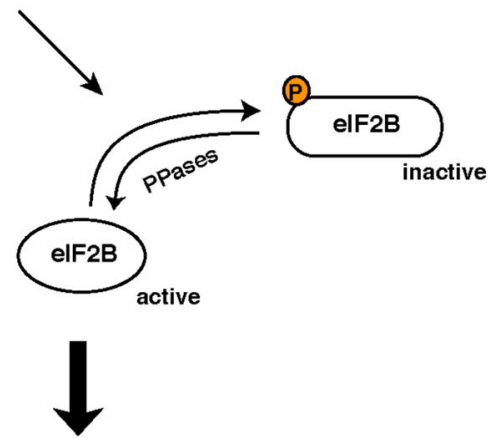

Regulation of protein synthesis

Figure 2. Regulation of GSK-3 by the insulin-signal transduction pathway

The binding of insulin to its cell surface receptor triggers the recruitment and activation of PI3K. At the plasma membrane, PI3K stimulates the formation of

phosphatidylinositol-3,4,5trisphosphate (PtdIns $(3,4,5) \mathrm{P} 3)$ which triggers the colocalisation of phosphoinositide dependent kinase 1 (PDK1) and PKB allowing PDK1 to activate PKB. Upon activation, PKB phosphorylates and inactivates GSK-3 resulting in the dephosphorylation of glycogen synthase and eIF2B, two substrates of GSK-3 that control the rates of glycogen metabolism and protein synthesis respectively. 


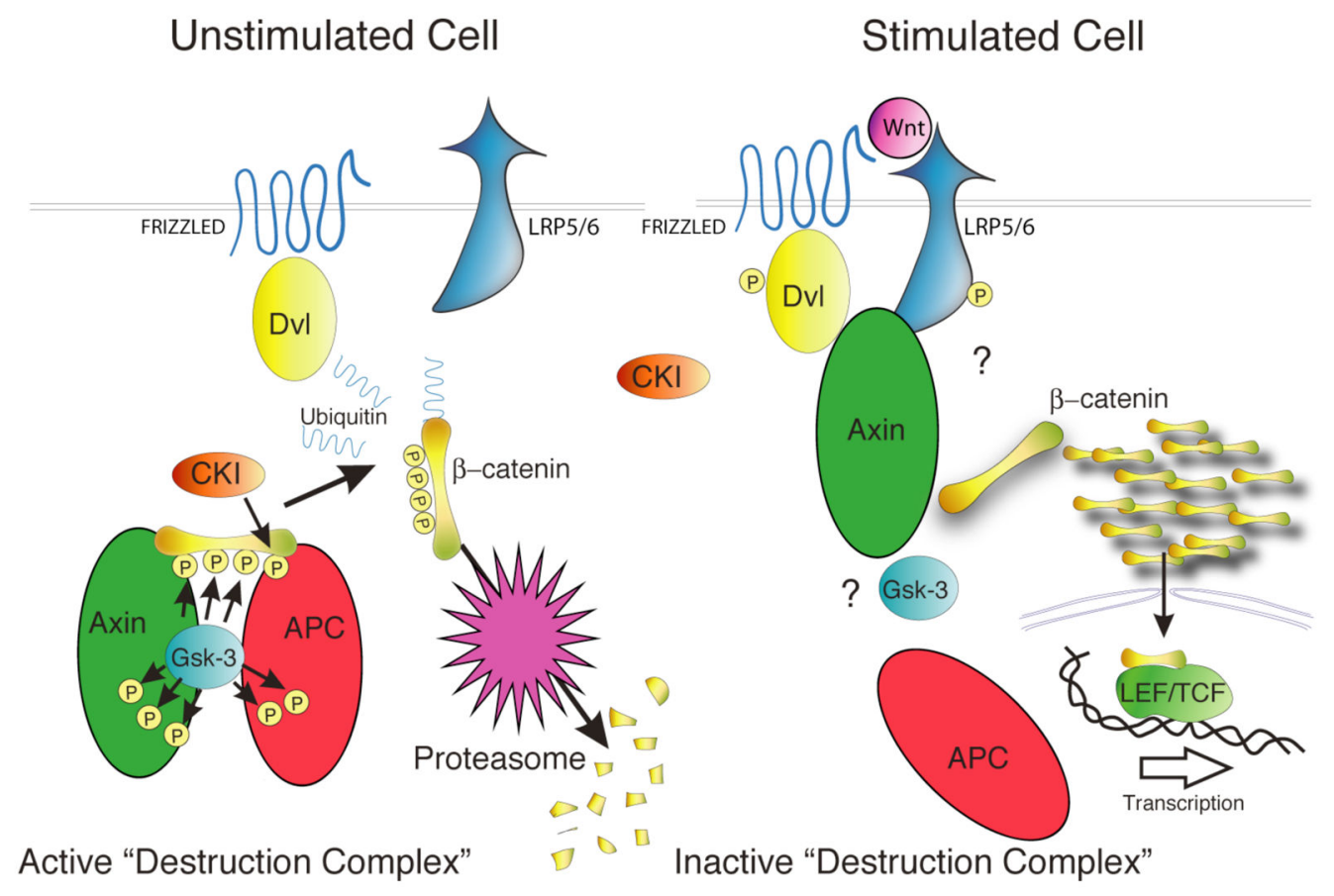

Fig. 3. Central Role of GSK-3 in the Wnt/ $\beta$-catenin Pathway

In unstimulated cells, a minimal complex of GSK-3, axin, APC and $\beta$-catenin is required for GSK-3-mediated phosphorylation of $\beta$-catenin which targets it for ubiqitination and degradation. Wnt stimulation activates the receptor Frizzled, and co-receptor LRP5/6, that then signal through Dishevelled, using an unclear mechanism, to inactivate $\beta$-catenin phosphorylation. Unphosphorylated $\beta$-catenin accumulates and translocates to the nucleus where it transactivates genes regulated by TCF/LEF transcription factors. 